\title{
1. The AI momentum
}

Technology and its interactions with humans has long captivated writers. An extensive and wide-ranging literature covered artificial intelligence technology for the past decades in the fields of computer science, ${ }^{1}$ philosophy and legal thinking, ${ }^{2}$ religion, ${ }^{3}$ and ethics. ${ }^{4}$ Even the conservative field of legal services has not eluded AI technology influence. ${ }^{5}$ Predictions about future applications

1 Nils J Nilsson, The Quest for Artificial Intelligence: A History of Ideas and Achievements (CUP 2010) 19 <ai.stanford.edu/ nilsson/QAI/qai.pdf> accessed 3 September 2020; Richard E Neapolitan and Xia Jiang, Artificial Intelligence: With an Introduction to Machine Learning (2nd edn, Taylor and Francis Group, LLC 2018); Pamela McCorduck, Machines Who Think: A Personal Inquiry into the History and Prospects of Artificial Intelligence (W H Freeman and Company 1979); Vincent C Müller (ed.), Fundamental Issues of Artificial Intelligence (Springer International Publishing Switzerland 2016); Vincent C Müller (ed.), Philosophy and Theory of Artificial Intelligence (Springer-Velrag Berlin Heidelberg 2013).

2 See Aristotle, The Politics (T A Sinclair tr, Penguin 1962) 31; Thomas Hobbes, Leviathan (C B Macpherson ed., first published 1651, Penguin 1968) 81; Yuval Noah Harari, 21 Lessons for the 21st Century (Penguin Random House Canada 2018); Nick Bostrom, Superintelligence: Paths, Dangers, Strategies (OUP 2014); Kevin Kelly, What Technology Wants (Viking 2010); Ray Kurzweil, The Singularity Is Near: When Humans Transcend Biology (Penguin 2005).

3 Jewish folklore contains stories about an animated anthropomorphic being that was created from clay or mud, called Golem. See Yudl Rosenberg, The Golem and the Wondrous Deeds of the Maharal of Prague (Curt Leviant tr, Yale University Press 2007). See also Nachshon (Sean) Goltz, John Zeleznikow, Tracey Dowdeswell, 'From the Tree of Knowledge and the Golem of Prague to Kosher Autonomous Cars: The Ethics of Artificial Intelligence Through Jewish Eyes' [2020] OJLR 1.

4 Patrick Lin, Keith Abney and Ryan Jenkins (eds), Robot Ethics 2.0: From Autonomous Cars to Artificial Intelligence (OUP 2017); Nick Bostrom and Eliezer Yudkowsky, 'The Ethics of Artificial Intelligence' in Keith Frankish and William M Ramsey (eds), The Cambridge Handbook of Artificial Intelligence (CUP 2014) 316-334; Burkhard Schafer and others, 'A Fourth Law of Robotics?: Copyright and the Law and Ethics of Machine Co-Production' (2015) 23:3 AI \& L 217; See also Stuart Russell and Peter Norvig (eds), Artificial Intelligence A Modern Approach (3rd edn, Prentice Hall 2010) 1034-1040.

5 See Giuseppina D'Agostino, Aviv Gaon and Carole Piovesan (eds), Leading Legal Disruption: Artificial Intelligence and a Toolkit for Lawyers and the Law (Thompson Reuters Canada 2021); See also Richard Susskind and Daniel Susskind, The Future of the Professions: How Technology Will Transform the Work of Human Experts (OUP 2015) 9; Benjamin Alarie, Anthony Niblett and Albert H Yoon, 'Law in 
of AI-based technology fill our books, academic papers, and news. Think about the prospects of caregivers' robots for the elderly, nanny robots for infants, or the promise of AI doctors. ${ }^{6}$

Indeed, AI is changing our way of life, affecting areas such as transportation, ${ }^{7}$ health, ${ }^{8}$ employment, ${ }^{9}$ entertainment and journalism, ${ }^{10}$ government services, ${ }^{11}$ and may even provide an alternative to human relations. ${ }^{12}$ In the

the Future' (2016) 66:4 UTLJ 423; Jesse Beatson, 'AI-Supported Adjudicators: Should Artificial Intelligence Have a Role in Tribunal Adjudication?' (2018) 31 CJALP 307; Kevin D Ashley, Artificial Intelligence and Legal Analytics: New Tools for Law Practice in the Digital Age (CUP 2017); Lauren H Scholz, 'Algorithmic Contracts' (2017) 20 Stan Tech L Rev 128.

6 Robot doctors could take care of infected COVID-19 patients, for example. See Matt Simon, 'The Covid-19 Pandemic Is a Crisis That Robots Were Built For' Wired (New York, 25 March 2020) <wired.com/story/covid-19-pandemic-robots> accessed 3 September 2020.

See Guy Seidman and Aviv Gaon, 'A Future Without Human Driving' (2020) 18 Geo J L \& Pub Pol'y 503; See also US National Science and Technology Council and the Department of Transportation, Ensuring American Leadership in Automated Vehicle Technologies: Automated Vehicles 4.0 [2020] <https://transportation.gov/ sites/dot.gov/files/2020-02/EnsuringAmericanLeadershipAVTech4.pdf $>$ accessed 3 September 2020; Peter Stone and others, 'Artificial Intelligence and Life in 2030 One Hundred Year Study on Artificial Intelligence: Report of the 2015-2016 Study Panel' (Stanford University Press 2016) 18<ai100.stanford.edu/2016-report> accessed 3 September 2020 [The One Hundred Year Study].

8 I Glenn Cohen, Holly Fernandez Lynch and Effy Vayena (eds), Big Data, Health Law, and Bioethics (CUP 2018); The One Hundred Year Study (n 7) 25.

9 See Spyros Makridakis, 'The Forthcoming Artificial Intelligence (AI) Revolution: Its Impact on Society and Firms' (2017) 90 Futures 46, 53; Harari (n 2) chapter 2; Michael A Peters, 'Technological Unemployment: Educating for the Fourth Industrial Revolution' (2017) 5:1 Journal of Self-Governance and Management Economics 25. For different views see Mark Lemley, 'IP in a World Without Scarcity' (2015) 90 NYU L Rev 460, 513. See also US, Executive Office of the President, Artificial Intelligence, Automation, and the Economy [2016] <obamawhitehouse.archives.gov/ sites/whitehouse.gov/files/documents/Artificial-Intelligence-Automation-Economy .PDF> accessed 3 September 2020 [AI and the Economy].

10 Noam L Latar, Robot Journalism: Can Human Journalism Survive? (World Scientific Publishing Co Pte Ltd 2018) 29; Virtual and augmented reality have great potential for the entertainment industry. See Mark Lemley and Eugene Volokh, 'Law, Virtual Reality, and Augmented Reality' (2018) 166:5 Penn St L Rev 1051.

11 Aviv Gaon and Ian Stedman, 'A Call to Action: Moving Forward with the Governance of Artificial Intelligence in Canada' (2019) 56:4 Alta L Rev 1137.

12 See Ian Yeoman and Michelle Mars, 'Robots, Men and Sex Tourism' (2012) 44 Future 365; Noel Sharkey and others, 'Our Sexual Future with Robots' [2017] Foundation for Responsible Robotics < responsible-robotics-myxf6pn3xr.netdna-ss1 .com/wp-content/uploads/2017/11/FRR-Consultation-Report-Our-Sexual-Future-with -robots-1-1.pdf> accessed 27 April 2020. 
coming era of social distancing, AI might become a human necessity. ${ }^{13}$ Others view expected developments in $\mathrm{AI}$ as a threat to humanity. The late theoretical physicist, Stephen Hawking, stated that 'success in creating AI would be the biggest event in human history. Unfortunately, it might also be the last.' Elon Musk shares Hawking's assessment, saying that if he had to guess what humanity's biggest risk is, AI might be it. ${ }^{14}$

I do not share these ominous predictions. As the One Hundred Year Study suggests, with all the risks AI might pose to humanity, it has a greater positive potential. ${ }^{15}$ Nevertheless, we should embrace AI technology with caution, addressing the many legal, ethical, and technological challenges posed by AI. ${ }^{16}$

AI technology is, in some respects, older than many people realize. The term 'artificial intelligence' was coined during the mid-1950s ${ }^{17}$ However, the origins of AI as a field of research go back to Alan Turing's investigations of computer intelligence. ${ }^{18}$ Though many continued Turing's research in the ensuing decades, it was not until the mid-late 1990s or early 2000s that AI gained momentum as a field. ${ }^{19}$

13 Richard Susskind and Daniel Susskind, The Future of the Professions: How Technology Will Transform the Work of Human Experts (OUP 2015).

14 Stephen Hawking and others, "Stephen Hawking: "Transcendence looks at the implications of artificial intelligence - but are we taking AI seriously enough?", The Independent (London, 1 May 2014) <independent.co.uk/news/science/stephen -hawking-transcendence-looks-at-the-implications-of-artificial-intelligence-but-are -we-taking-9313474.html> accessed 27 April 2020; Samuel Gibbs, 'Elon Musk: Artificial Intelligence Is Our Biggest Existential Threat' The Guardian (London, 27 October 2014) <theguardian.com/technology/2014/oct/27/elon-musk-artificial -intelligence-ai-biggest-existential-threat $>$ accessed 3 September 2020.

15 The One Hundred Year Study (n 7) 6; See Eric Sofge, 'Why Artificial Intelligence Will Not Obliterate Humanity: It's Not Smart Enough to Turn Sinister' (Popular Science, 19 March 2015) <popsci.com/why-artificial-intelligence-will-not -obliterate-humanity> accessed 3 September 2020.

16 Ryan Calo, 'Artificial Intelligence Policy: A Primer and a Road Map' (2017) 51:2 UC Davis L Rev 399, 431.

17 Russell and Norvig (n 4); McCorduck (n 1); John McCarthy and others, 'A Proposal for the Dartmouth Summer Project on Artificial Intelligence' (Dartmouth University 1955) <www-formal.stanford.edu/jmc/history/dartmouth/dartmouth.html> accessed 3 September 2020 [The Dartmouth Proposal].

18 Alan M Turing, 'Computing Machinery and Intelligence' [1950] LIX:236 Mind 433. Alan Turing was a British mathematician who played a major role during the Second World War in the decryption of the infamous Nazi 'Enigma' machine.

19 US, Executive Office of the President, Preparing for the Future of Artificial Intelligence (2016) 5-6 < obamawhitehouse.archives.gov/sites/default/files/whitehouse files/microsites/ostp/NSTC/preparing_for_the_future_of_ai.pdf $>$ accessed 3 $\bar{S}$ eptember 2020 [Preparing for the Future of AI Report]; US, Executive Office of the President, The National Artificial Intelligence Research and Development Strategic 
In his popular book, The Singularity Is Near: When Humans Transcend Biology, ${ }^{20}$ Ray Kurzweil reflects on the future of humanity in the upcoming decades of meta-ideas and mass information. ${ }^{21}$ Kurzweil defines singularity as 'a future period during which the pace of technological change will be so rapid, its impact so deep, that human life will be irreversibly transformed'. ${ }^{22}$ 'The key idea,' explains Kurzweil, 'is that the pace of change of our human-created technology is accelerating, and its powers are expanding at an exceptional pace. ${ }^{23}$ Given recent developments, Kurzweil argues that information-based technology will engulf all human knowledge and proficiencies. We can find support for Kurzweil's predictions in books, articles, and scientific progress. ${ }^{24}$ However, not everyone shares Kurzweil's optimism. ${ }^{25}$ Despite the progress in recent years, most of the AI advancement has been made in an area considered 'narrow AI'. Little progress has been attributed in 'general AI' ${ }^{26}$

A prudent approach might prove to be a good idea. After all, humanity is inclined to reject revolutionary ideas until they materialize. In 1828, it was the famous economist Jean-Baptiste Say who concluded that no machine would ever be able to perform what even the worst horses could. ${ }^{27}$ He was wrong. In less than 200 years, humanity moved from horses to automated vehicles. From a historical perspective, these advancements were as fast as a lightning strike.

Plan (2016) $12<$ nitrd.gov/PUBS/national_ai_rd_strategic_plan.pdf $>$ accessed 3 September 2020 [US AI Strategic Plan]; The One Hundred Year Study (n 7) 50-2.

${ }_{20}$ Kurzweil (n 2) 7; See also Murray Shanahan, The Technological Singularity (MIT Press 2015).

21 Kurzweil (n 2) 3.

22 ibid.

23 ibid 7-8.

24 Raymond Perrault and others, Artificial Intelligence Index Report 2019 (AI Index Steering Committee, Human-Centered AI Institute, Stanford University 2019); See also Gordon E Moore, 'Moore's Law at 40' in David C Brock (ed.), Understanding Moore's Law: Four Decades of Innovation (Chemical Heritage Foundation 2006); Vincent C Müller and Nick Bostrom, 'Future progress in artificial intelligence: A survey of expert opinion' in Vincent C Müller (ed.), Fundamental Issues of Artificial Intelligence (Springer Berlin 2016) 553; Bostrom (n 2).

25 Some predictions turned out to be false, see Stuart Armstrong, 'Assessing Kurzweil Predictions About 2019: The Results' (Lesswrong blog, 6 May 2020) <www .lesswrong.com/posts/NcGBmDEe5qXB7dFBF/assessing-kurzweil-predictions-about -2019-the-results?fbclid=IwAR1UYj9vDXSmqsBbSEURraOLLpC35a97JLImxDG jIdPW2Lfyj45aVUypdGw $>$ accessed 3 September 2020.

26 US AI Strategic Plan (n 19) 14. The UK report on AI has reached a similar conclusion. See UK, Select Committee on Artificial Intelligence, AI in the UK: Ready, Willing and Able? (16 April 2018) 15 <www.publications.parliament.uk/pa/ld201719/ ldselect/ldai/100/100.pdf $>$ accessed 3 September 2020 [The AI in the UK Report].

27 Jean B Say, Cours Complet D'economie Politique Pratique (Chez Rapilly 1828). 
In the past decade, several surveys and studies have sought to answer the very same and intriguing question - when will we reach high-level machine intelligence? Indeed, with no substantive scientific evidence that can point to a conclusive result, expert opinions might be the most reliable source we have to establish whether an AI revolution is indeed upon us, and if so, when.

The first surveys were taken in 2006 and 2007. In 2006, attendees of the AI@50 conference were given a set of questions. Forty-one per cent agreed that computers would be able to simulate every aspect of human intelligence in more than 50 years, while the same percentage thought this scenario would never happen. ${ }^{28}$ Bruce Klein took a different survey the following year. ${ }^{29}$ Klein asked only one specific question: 'When would AI surpass human intelligence?' Most respondents expressed the notion that AI will surpass human intelligence during the next half of the century. ${ }^{30}$

The next survey was initiated during the second conference on artificial general intelligence held in 2009 (AGI-09). ${ }^{31}$ The AGI-09 attendees (21 in total) were given a survey on the theme of 'How long till AGI?'32 According to Baum, Goertzel and Goertzel, '[M]ost experts expect human-level AI to be reached within upcoming decades, and all experts give at least some chance that some milestones will be reached within this time. ${ }^{33}$ Not surprisingly, most respondents believe that massive AI funding 'would cause the AI milestones to

28 Seth D Baum, Ben Goertzel and Ted G Goertzel, 'How Long Until Human-Level AI? Results from an Expert Assessment' (2011) 78:1 Tech Forecasting \& Soc Change 185, 186. See also <aiimpacts.org/ai50-survey> accessed 3 September 2020.

29 Klein's survey is hard to access, though mentioned in both Müller and Bostrom (n 24) and Baum, Goertzel and Goertzel (n 28) 187. There are several limitations to Klein's survey. First, it is an informal study. Klein relies on a broad population -888 responses - that consists of non-experts. Second, the study focuses on one issue superhuman AI.

$30150(17 \%)$ stated that superhuman AI will be reached between 2020 and 2030 while $231(26 \%)$ believed superhuman AI will be reached between 2030 and 2050. 81 (9\%) responded that superhuman AI is expected beyond the year 2100. Only 64 (7\%) responded that superhuman AI will never happen. Baum, Goertzel and Goertzel (n 28) 187.

31 James Barrat and Ben Goertzel, 'How Long Till AGI? - Views of AGI-11 Conference Participants' [2011] < hplusmagazine.com/2011/09/16/how-long-till-agi -views-of-agi-11-conference-participants> accessed 3 September 2020.

32 Baum, Goertzel and Goertzel (n 28) 188. The participants 'have a range of levels of expertise, from graduate students to senior researchers'.

33 ibid 185. Seventy-five per cent expect that AI will pass the Turing test by 2050 and $50 \%$ believe that AI will reach the stage of superhuman by the year 2045. Most experts assume, with almost certainty, that AI will surpass human capabilities by the end of this century, ibid 189-190. 
be reached sooner'. ${ }^{34}$ Finally, Vincent Müller and Nick Bostrom's 2016 study collected predictions from 550 AI experts. The survey focused on individuals from four different groups: AI philosophers and theorists, technical experts, members of the Greek Association for AI, and top AI authors. ${ }^{35}$ Müller and Bostrom were interested in the probability of a high-level machine intelligence (HLMI) in the future. Most of the respondents asserted that AI was likely to reach human ability by $2040-50$ (over 50\%), ${ }^{36}$ and $90 \%$ believe it is very likely to happen by 2075 . Ten per cent responded that after reaching human capacity, it would take two more years for an AI to achieve superintelligence, while $75 \%$ thought that it would take longer - up to 30 years (or less). Only $31 \%$ believed that these developments would turn out to be bad or extremely bad for humanity. Given the futuristic nature of these questions, no expert can provide any substantial evidence for such forecasts. Few have expressed their concern about the validity of the surveys and the conclusions. Oren Etzioni shared his scepticism, arguing that there is simply not enough data to support those predictions. ${ }^{37}$

The studies I have outlined offer different perspectives to the prospect of AI intelligence. It seems that there is a consensus that we will reach human-level intelligence (or artificial general intelligence) within the next three decades (between 2020 and 2050) and, following singularity, superhuman intelligence is expected soon after. Among the many experts, only a small fraction is willing to indicate that we will never achieve human-level intelligence. ${ }^{38}$ Thus, there is overwhelming support among leading experts for the probability that AI will reach singularity in the coming decades. However, it might not matter when exactly singularity happens. Whenever it might be reached, there is no

34 ibid 190. During the same year that Baum, Goertzel and Goertzel published their study, James Barrat conducted an informal survey of his own among 200 attendees of the 2011 Artificial General Intelligence conference (AGI-11). Barrat's informal survey, published later in his book, showed similar results to the AGI-09 survey. See James Barrat, Our Final Invention: Artificial Intelligence and the End of the Human Era (Thomas Dunne Books 2013).

35 Müller and Bostrom (n 24) 2.

36 ibid 14-5. Kurzweil 'set the date for the Singularity - representing a profound and disruptive transformation in human capability - as 2045. The nonbiological intelligence created in that year will be one billion times more powerful than all human intelligence today.' See Ray Kurzweil, 'Singularity Q\&A' (Kurzweil accelerating intelligence, 9 December 2011) < kurzweilai.net/singularity-q-a $>$ accessed 3 September 2020.

37 Oren Etzioni, 'No, the Experts Don't Think Superintelligent AI is a Threat to Humanity' (MIT Technology Review, 20 September 2016) <technologyreview $. \mathrm{com} / \mathrm{s} / 602410 /$ no-the-experts-dont-think-superintelligent-ai-is-a-threat-to-humanity $>$ accessed 3 September 2020.

38 Müller and Bostrom (n 24) 11. 
reason not to be planning for its legal consequences. A review of the recent history of computer science developments can provide guidance, allowing us to understand better what lies ahead.

\section{A LOOK BACK - A BRIEF HISTORY OF AI}

AI development began with dreams. Throughout history, humans have always been fascinated by the concept of non-human creations. Pamela McCorduck has traced several routes to AI: imagination ('what might be'); philosophical inquiry ('the bridge between imagination and what is'); what is or present realities ('artificial intelligence as it has been realized since the development of the digital computer'). ${ }^{39}$ In the 'imagination era', AI was treated much like the product of the gods, created to protect or threaten humans. However, imagination was only the beginning with the introduction of automata in the 16th century. Soon what people perceived as the power of the gods came to life. ${ }^{40}$ By the 19th century, the AI 'that penetrated and dwelled in people's imaginations [was] composed of the printed word rather than wood and metal and cloth'. ${ }^{41}$

Russell and Norvig argue that the first AI work was done by Warren McCulloch and Walter Pitts in 1943. McCulloch and Pitts "proposed a model of artificial neurons in which each neuron is characterized as being "on" or "off", with a switch to "on" occurring in response to stimulation by a sufficient number of neighboring neurons'.$^{42}$ In 1946, Alan Turing thought about the idea of an intelligent computer playing chess as an example. ${ }^{43}$ Turing is best known for his 'imitation game', the name Turing gave to his so-called 'AI' test (i.e. the Turing test). In 1950, Turing published the paper 'Computing Machinery and Intelligence', ${ }^{44}$ in which he argued for the possibility of creating a human level of intelligence in computer programs. In 1952, Turing played a game 'in which he simulated the computer, taking about half an hour per move' as he possessed no computer with the requisite capabilities ${ }^{45}$ Turing aspired to 'test

\footnotetext{
39 McCorduck (n 1) 4.

40 ibid 13.

${ }^{41}$ ibid 15. E T A Hoffman, The Sandman (1815); Mary Shelley, Frankenstein (1818); Isaac Asimov, The Rules of Robotics (1950).

42 Russell and Norvig (n 4) 16. The first neural network computer (called the SNARC) was built by Marvin Minsky and Dean Edmonds in 1950.

43 Nilsson (n 1) 123; McCorduck (n 1) 50.

44 Turing (n 18). For further discussions about Turing research see Robert Epstein, Gary Roberts and Grace Beber (eds), Parsing the Turing Test: Philosophical and Methodological Issues in the Quest for the Thinking Computer (Springer 2008).

45 Nilsson (n 1) 123; The game is available online: <chessgames.com/perl/ chessgame? gid=1356927 $>$ accessed 3 September 2020 .
} 
whether the artifact was indistinguishable from a person with regard to what he took to be pertinent property, verbal behavior' ${ }^{46}$

Turing proposed to answer the question, 'Can machines think?' However, Turing rejected the idea of defining the terms 'machine' and 'think' with the common use of the words. Turing claimed that this attitude is 'dangerous', and might make it 'difficult to escape the conclusion that the meaning and the answer to the question, "Can machines think?" is to be sought in a statistical survey such as a Gallup poll'. Turing's test was designed to establish which element in the 'game' is human and which is machine through verbal interrogation; if the interrogator cannot ascertain which of the players is human, the machine has passed the imitation game, since the machine is able to imitate human behaviour. However, even if a machine does 'pass' the imitation test and 'tricks' the human interrogator, it does not mean that this machine is indeed capable of thoughts and possesses intelligence. ${ }^{47}$

The first stage of AI development following the Turing era was nicknamed the 'toy problem' stage. As Nils Nilsson explains, 'Solving puzzles, playing games such as chess and checkers, ${ }^{48}$ proving theorems, answering simple questions, and classifying visual images were among some of the problems tackled by the early pioneers during the 1950 s and early 1960 s. ${ }^{49}$ During that decade, three important meetings coincided with the emergence of AI as a full-fledged field of research: the 1955 Session on Learning Machines that was held in conjunction with the 1955 Western Joint Computer Conference in Los Angeles; the 1956 Summer Research Project on AI held at Dartmouth College in Hanover, New Hampshire; and the 1958 symposium on the Mechanization of Thought Processes held at the National Physical Laboratory, Teddington, Middlesex, England. ${ }^{50}$

The Dartmouth workshop is considered the first conference to coin the term AI. ${ }^{51}$ The workshop was spearheaded by the founding fathers of AI: John

46 Stuart Shieber (ed.), The Turing Test: Verbal Behavior as the Hallmark of Intelligence (MIT Press 2004) Introduction.

47 ibid. See also Michael Scriven, 'The Mechanical Concept of Mind' (1953) 62:246 Mind 230.

48 Nilsson (n 1) 253 concludes: 'These years, the late 1960s through the mid-1970s, saw computer chess programs gradually improving from beginner-level play to middle-level play. Work on computer chess during the next two decades would ultimately achieve expert-level play (...).'

49 Nilsson (n 1) 71.

50 ibid 73 .

51 McCorduck (n 1) 96, opines: 'A dispute occurred over what the new field should be named. Although the conference was officially called The Dartmouth Summer Research Project on Artificial Intelligence, many attendees balked at that term, invented by [John] McCarthy.' McCorduck further quoted McCarthy recollections 
McCarthy (mathematician), Nathaniel Rochester (computer scientist), Claude Shannon (mathematician), and Marvin Minsky (cognitive scientist). ${ }^{52}$ The scope of the workshop was described in the proposal written by McCarthy for the Rockefeller Foundation in August 1955..$^{53}$ The Mechanization of Thought Processes symposium was the third important event in the field of AI. Held in the UK in 1958, only a few years after the conclusion of the Dartmouth workshop, the symposium's goal was 'to bring together scientists studying artificial thinking, character and pattern recognition, learning, mechanical language translation, biology, automatic programming, industrial planning and clerical mechanization'. ${ }^{54}$ Several of the papers that were presented during this symposium influenced the history of AI significantly.

From the early stages of AI development, researchers felt confident enough to share their predictions about the foreseeability of AI success. Herbert Simon, for example, stated that 'within 10 years a computer would be chess champion, and a significant mathematical theorem would be proved by machine' ${ }^{55}$ These predictions would come true four decades later.

During the 1950s and 1960s, scientists were focused on the Logic Theorist (LT) software ${ }^{56}$ as well as pattern recognition ${ }^{57}$ of two-dimensional segments such as photographs or pages. Russell and Norvig outline three difficulties AI faced during that decade. First, 'early programs knew nothing of their subject

from the conference, stating 'I [McCarthy] won't swear that I hadn't seen it before ... but artificial intelligence wasn't a prominent phrase particularly. Someone may have used it in a paper or a conversation or something like that, but there were many other words that were current at the time. The Dartmouth workshop made that phrase dominate the others.'

52 Nilsson (n 1) 80. Nilsson concludes that 'the 1956 workshop is considered to be the official beginning of serious work in artificial intelligence, and Minsky, McCarthy, Newell, and Simon came to be regarded as the "fathers" of AI.'

53 ibid 77; The Dartmouth Proposal (n 17): 'The study is to proceed on the basis of the conjecture that every aspect of learning or any other feature of intelligence can in principle be so precisely described that a machine can be made to simulate it. An attempt will be made to find how to make machines use language, form abstractions and concepts, solve kinds of problems now reserved for humans, and improve themselves. (...) For the present purpose the artificial intelligence problem is taken to be that of making a machine behave in ways that would be called intelligent if a human were so behaving.'

54 Nilsson (n 1) 81, quoting the preface for the symposium.

55 Russell and Norvig (n 4) 21.

56 LT was invented by three scientists - Allen Newell, Herbert Simon, and Cliff Shaw - associated with RAND corporation in Santa Monica and Carnegie Tech in Pittsburgh. See McCorduck (n 1) 104-108. LT is considered one of the first AI programs.

57 The process of analysing images, signals, or voices and classifying it into categories. See Nilsson (n 1) 89. 
matter; they succeeded by means of simple syntactic manipulations. ${ }^{58}$ The attempts to translate Russian scientific papers after Sputnik's launch in 1957 serve as a vivid example of this difficulty. As every Google-translate user knows today, it is highly complex to translate words in their original context, and an accurate translation requires a background in both languages to resolve ambiguities. For this reason, the early attempts to use programs in these efforts failed miserably. Subsequently, the US government dropped the idea, and all the funding for academic translation was cancelled. The second difficulty 'was the intractability of many of the problems that AI was attempting to solve'. Third, there were 'some fundamental limitations on the basic structures being used to generate intelligent behavior' ${ }^{59}$

During the 1960s and into the 1970s, AI research progressed modestly. Developmentsinthe 1960swereinfluenced by severalfactors, includingnewcomputer languages, computer vision, ${ }^{60}$ mobile robots, ${ }^{61}$ problem-solving of mechanizing intelligent behaviour, ${ }^{62}$ government agencies support, ${ }^{63}$ and the founding of the Automatic Language Processing ${ }^{64}$ Advisory Committee (ALPAC). ${ }^{65}$

\footnotetext{
$58 \quad$ Russell and Norvig (n 4) 21.

59 ibid 21-22.
}

60 ibid 169. In the early 1960s, Woodrow W Bledose, Charles Bisson, and Helen Chan, with the support of the CIA, developed facial recognition techniques. However, '[f]ace recognition programs of the 1960s and 1970s had several limitations. They usually required that images be of faces of standard scale, pose, expression, and illumination.' ibid 173.

${ }_{61}$ ibid 213. During that time, several groups began to work on mobile robots.

62 ibid 157-60.

63 Such as the Office of Naval Research (ONR) and the Advanced Research Projects Agency (ARPA).

${ }_{64}$ Nilsson (n 1) 141, explains the concept of natural language processing: 'Beyond pattern recognition of individual alphanumeric characters, whether they be of fixed font or handwritten, lies the problem of understanding strings of characters that form words, sentences, or larger assemblages of text in a "natural" language, such as English.'

65 ibid 150, refers to John R Pierce and others, Language and Machines: Computers in Translation and Linguistics (The National Academies Press 1966) ALPAC Report. In 1968 ALPAC changed its name to the Association for Computational Linguistics (ACL). W John Hutchins stated that the pessimistic report of ALPAC at the beginning of the decade resulted in an end to research in this area: 'The influence of the ALPAC report was profound. It brought a virtual end to MT research in the USA for over a decade and MT was for many years perceived as a complete failure (...) The focus of MT activity switched from the United States to Canada and to Europe.' Hutchins therefore calls the period between 1967 and 1976 'the quiet decade'. Nilsson (n 1) 237. See also W John Hutchins, 'Machine Translation: A Brief History' in E F K Koerner and R E Asher (eds), Concise History of the Language Sciences: From the Sumerians to the Cognitivists (Pergamon Press 1995) 431-45. 
Books $^{66}$ and conferences also promoted developments in the field of AI during this decade. ${ }^{67}$

The 1970s saw a shift from 'toy problems' and controlled laboratory environments toward applied work dealing with 'real world' issues. Nilsson points to two possible reasons for this shift: the increase in power of AI methods and US government investment in research relevant to military needs. ${ }^{68}$ The $1970 \mathrm{~s}$ witnessed an increase in speech recognition research as well, ${ }^{69}$ and a study group was formed 'to make recommendations concerning the launching of a major Defense Advanced Research Projects Agency (DARPA) - supported project in speech understanding' ${ }^{70}$ By the mid-1970s, the pressure for militarily useful systems intensified, and DARPA focused on shifting resources based on the agenda of the US Department of Defense (DoD). ${ }^{71}$ Computer vision 'grew into a highly developed subspecialty of AI, joining other specialized

66 Such as Edward A Feigenbaum and Julian Feldman, Computers and Thought (McGraw-Hill 1963); Nils J Nilsson, Learning Machines: Foundations of Trainable Pattern-Classifying Systems (McGraw-Hill 1965); Frank Rosenblatt, John T Farrow and Sam Rhine, 'The Transfer of Learned Behavior from Trained to Untrained Rats by Means of Brain Extracts. I' (1966) 55 PNAS 548; Marvin Minsky and Seymour Papert, Perceptrons: An Introduction to Computational Geometry (MIT Press 1969); Nils J Nilsson, Problem-Solving Methods in Artificial Intelligence (McGraw-Hill 1971); James R Slagle, Artificial Intelligence: The Heuristic Programming Approach (McGraw-Hill Book 1971); Bertram Raphael, The Thinking Computer: Mind Inside Matter (W H Freeman 1976).

${ }_{67}$ Nilsson (n 1) 155 and 261. In 1969, Donald E Walker and Alistair Holden organized the International Joint Conference on AI (IJCAI) in Washington, DC. It was the first large AI-devoted conference. Subsequent conferences were held in London (1971), North America, and other regions of the world.

68 ibid 265. See also Joseph Weizenbaum, Computers, Power, and Human Reason: From Calculation to Judgment (W H Freeman 1976) 271-72, arguing that AI technology originated in the academia and military.

69 Nilsson (n 1) 267. Speech recognition is 'the process of converting an acoustic stream of speech input, as gathered by a microphone and associated electronic equipment, into a text representation of its component words'. The process is complicated because many words sound similar. Attempts to develop speech recognition began at Bell Laboratories in the 1930s. The work continued during the 1950s and the 1960s. ibid 269.

70 ibid 270. The study group held several meetings and delivered its final report to DARPA. In 1971, Larry Roberts established at DARPA a five-year speech-understanding project based largely on the study group's work.

71 ibid 310. Nilsson describes the suggestions of George Heilmeier (DARPA's then-director): '[G]et computers to read Morse code in the presence of other code and noise; get computers to identify/detect key words in a stream of speech; solve DoD's "software problem"; make a real contribution to command and control, and; do a good thing in sonar.' ibid 312. 
areas such as natural language processing, robotics, knowledge representation, and reasoning, ${ }^{72}$

The early 1980s saw progress in expert systems and AI technologies such as image and speech understanding, as well as natural language processing. This accompanied dramatic progress in communications technology, computer networks, and processing technology. ${ }^{73}$ The American Association for Artificial Intelligence (AAAI) ${ }^{74}$ was founded in this decade, as was Japan's Fifth Generation Computer System AI initiative. ${ }^{75}$ The goal of the Japanese initiative 'was to produce computers that could perform AI-style inferences from large data and knowledge bases and communicate with humans using natural language'. ${ }^{76}$ The Fifth Generation, besides having sophisticated software, was built to involve many parallel processors using ultra-large-scale integration. ${ }^{77}$

Growing Japanese dominance in consumer electronics and manufacturing made the American computer industry worry that its world leadership in technology might be weakening. Concern about the Japanese initiative contributed to DARPA's new 'Strategic Computing Program', ${ }^{78}$ in which AI played a major role. ${ }^{79}$ The British reacted to the Japanese project by forming a committee, ${ }^{80}$ while the European Economic Community established the European Strategic Program of Research in Information Technology (ESPRIT) ${ }^{81}$

\section{2 ibid 327.}

73 ibid 359.

74 ibid 343. Founded in 1980. Known today as the Association for the Advancement of Artificial Intelligence. During the 1980s, membership in the AAAI reached a peak of more than 16,000 people. ibid 344 .

75 The phrase 'Fifth Generation' derived from earlier generations of computer technology such as World War II First Generation vacuum tubes, 1959 Second Generation transistors (that were connected with copper wires), 1960s Third Generation small-scale integration, and the 1970s Fourth Generation very large-scale integration.

76 Nilsson (n 1) 349.

77 ibid. In small-scale integration, "transistors and other components were fabricated on single silicon wafer "chips", and the several chips comprising a computer were connected together by wires'. In very large-scale integration, 'entire microprocessors could be put on a single chip'.

78 According to Nilsson, ibid 362, the program had three major applications in mind to gain military support: 'Pilot's Associate (for the Air Force), an aircraft carrier "Battle Management System" (for the Navy), and an "Autonomous Land Vehicle" (for the Army).' We might as well say that the idea for self-driving cars was planted back then. 79 ibid 359-61. As Nilsson explains, 'During the decade from 1983 to 1993 DARPA spent just over $\$ 1$ billion on SC.9. The plan envisioned supporting two main thrusts, namely, major projects that would build specific applications and basic research to develop the "technology base" that would be needed for those applications.'

80 ibid 355.

81 ibid 356. ESPRIT was EU's response to the Japanese initiative and its goal was to foster transnational collaboration within the EU and among research industries, organizations, and academic institutes. 
Throughout the 1980s, AI enjoyed increased popularity and commercial success. 'New results unfolded in all of its subfields, including reasoning and representation, machine learning, ${ }^{82}$ natural language processing, and computer vision' ${ }^{83}$ In the beginning of the 1980 s, many, including government and industry leaders, shared great expectations of the potential for AI. ${ }^{84}$ However, this honeymoon period did not last, and the end of the decade was nicknamed the 'AI Winter'. During the AI Winter, funding to AI was cut, and many companies went out of business. The common explanation for the change toward AI research is the high expectations driven by the overoptimism of AI scientists. When the realization grew that an AI singularity was not on the horizon, confidence in AI's ability sank, and with it, funding. ${ }^{85}$

The late 1980s also marked the growing interest of the legal community in AI. One significant event occurred in May 1987 with the first international conference on AI and law (known since as ICAIL) in Boston, USA. ${ }^{86}$ The ICAIL is considered the 'birth of an AI and Law community' ${ }^{87}$ Few other indications for the emergence of an AI and law community followed the establishment of what would soon become ICAIL traditions. First came the EU Jurix conferences that have been held since 1988 annually. Second came the

82 The term machine learning (or ML) is often conflated or misused with the term artificial intelligence. However, while AI might include ML, ML is only a particular type of AI. ML describes an algorithm's ability to improve with experience without being programmed when provided with enough data. See also David Lehr and Paul Ohm, 'Playing with the Data: What Legal Scholars Should Learn about Machine Learning' (2017) 51:2 UC Davis L Rev 653, 655. Lehr and Ohm explain ML as 'the name for a large family of techniques used for sophisticated new forms of data analysis that are becoming key tools of prediction and decision-making'. They divide the process of ML into eight steps: 'problem definition, data collection, data cleaning, summary statistics review, data partitioning, model selection, model training, and model deployment'.

83 Nilsson (n 1) 433.

84 Russell and Norvig (n 4) 24: As Russell and Norvig offer, 'Overall, the AI industry boomed from a few million dollars in 1980 to billions of dollars in 1988, including hundreds of companies building expert systems, vision systems, robots, and software and hardware specialized for these purposes.'

85 Nilsson (n 1) 409, indicates that during the AI Winter membership in the AAAI fell, DARPA budget to AI was cut from $\$ 47$ million to $\$ 31$ million, and '[a]dvertising in the AI Magazine dropped (...) as did participation by government and industry in AI conference exhibits. Several AI companies closed their doors, and AI research at some of the larger computer hardware and software companies was terminated.'

86 Trevor Bench-Capon and others, 'A history of AI and Law in 50 Papers: 25 Years of the International Conference on AI and Law' (2012) 20 AI \& L 216 [AI and Law in 50 papers].

$87 \mathrm{AI}$ and Law in 50 papers, ibid 217. Many central ideas in the AI field were introduced during ICAIL and developed in the following conferences. 
founding, in 1992, of the Artificial Intelligence and Law journal. Third came the holding of the International Association for AI and Law inaugural meeting in 1991 during the third ICAIL.

The 1990s and 2000s marked a new era for AI, as developments in computer science increased its potential. Since then, there were several significant achievements, mainly after the 1997 victory of IBM's Deep Blue computer over the chess champion Garry Kasparov. ${ }^{88}$ Following the new millennium, the term 'deep learning' was coined to explain algorithms that can distinguish between images, ${ }^{89}$ and in 2011, IBM's Watson, which was based on deep learning, won the trivia game show Jeopardy!. During the same year, DARPA developed CALO (Apple's Siri predecessor). In the following years, AI advancements moved faster than ever before with progress in areas such as transportation, education, national security, and health..$^{90}$ Machines are outsmarting humans not only in games but also in the labour market. Algorithms are increasingly being used in fields like insurance, finance, human resources, art, and medicine..$^{91}$

88 Preparing for the Future of AI Report (n 19).

89 Geoffrey Hinton, Simon Osindero and Yee-Whye Teh, 'A Fast Learning Algorithm for Deep Belief Nets' (2006) 18.7 Neural Computation 1527. Deep learning is a subset of machine learning with networks capability to learn from unclassified data (and with no human supervision). Also known as deep neural learning. See also Hinton's seminal paper about neural networks: Alex Krizhevsky, Ilya Sutskever and Geoffrey E Hinton, 'ImageNet Classification with Deep Convolutional Neural Networks' [2012] Advances in Neural Information Processing Systems 25 (NIPS 2012).

90 AI Index Report (n 24) 5-7. In the wake of the 2020 COVID-19 pandemic, AI technology is used for numerous purposes in the war against the virus. See Kelley A Wittbold and others, 'How Hospitals Are Using AI to Battle Covid-19' (Harvard Business Review, 3 April 2020) <hbr.org/2020/04/how-hospitals-are-using-ai-to-battle -covid-19> accessed 3 September 2020; Tom Taulli, 'AI (Artificial Intelligence) Companies That Are Combating the COVID-19 Pandemic' Forbes (New Jersey, 28 March 2020) < forbes.com/sites/tomtaulli/2020/03/28/ai-artificial-intelligence -companies-that-are-combating-the-covid-19-pandemic/\#dc8faf958f83> accessed 3 September 2020.

91 Benjamin Alarie, Anthony Niblett and Albert H Yoon, 'Focus Feature: Artificial Intelligence, Big Data, and the Future of Law' (2016) 66 UTLJ 423. In early 2016, an AI computer (AlphaGo) defeated a human master in the game of Go, and in January 2017, Libratus, an AI computer program, beat the best poker players in the world in matches worth more than $\$ 1.7$ million in chips. See Wikipedia, 'Go (game)' (last edited 2 October 2018) <en.wikipedia.org/wiki/Go_(game)> accessed 3 September 2020; Olivia Solon, 'Oh the humanity! Poker computer trounces humans in big step for AI' The Guardian (London, 31 January 2017) < theguardian.com/technology/2017/ jan/30/libratus-poker-artificial-intelligence-professional-human-players-competition> accessed 3 September 2020; Christies, 'Is artificial intelligence set to become art's next medium?' (Christies, 12 December 2018) <christies.com/features/A-collaboration 
This progress has become possible as a result of developments in AI research. Russell and Norvig suggest that one of the most important effects on AI research was the Internet: AI systems became very common in web-based applications, and AI technologies underlie many Internet tools such as search engines. ${ }^{92}$ During that time, researchers were drawn back to early aspirations to create a general intelligent agent - AI that can perform a wide range of tasks and can learn and use knowledge in a similar way to humans. Furthermore, AI has become dominant in other fields, creating a mixture of approaches, which in turn speeds up progress in areas such as robotic cars. ${ }^{93}$

In discussing the more recent history of AI, it is important to highlight the 2016 US reports that signalled a surge in international research and regulatory debate. The US AI Strategic Plan describes three waves of technological advancement in the past decades. The first focused on handcrafted knowledge, with a strong rule-based expert system in which the knowledge was collected by humans and expressed in 'if-then' rules. The second wave began with the new millennium and was characterized by the advancement of machine learning. The current wave of progress began around 2010 and is driven by three factors ${ }^{94}$ First is the availability of big data from sources, including social media, business, e-commerce, science, and government. Second, these data provide the raw material for improving machine-learning approaches and algorithms. Third, the latter, in turn, rely on the capabilities of more powerful computers. ${ }^{95}$ Further indication to the advancement in AI research is expressed

-between-two-artists-one-human-one-a-machine-9332-1.aspx $>$ accessed 3 September 2020.

92 Russell and Norvig (n 4) 26-27.

93 ibid 27. The most known example is John Laird, Allen Newell, and Paul Rosenbloom SOAR project: 'our approach to developing human-level agents is to study the cognitive architecture underlying general intelligence ... A cognitive architecture provides the fixed computational structures that form the building blocks for creating generally intelligent systems.' John E Laird, The Soar Cognitive Architecture (MIT Press 2012) 1.

94 It seems that we are moving toward a next phase of AI progress - explanatory and general AI technologies. See US AI Strategic Plan (n 19) 12-14.

95 Preparing for the Future of AI Report (n 19) 6, relying on the One Hundred Year Study (n 7) 8-9. In a hearing before the US Senate Committee on Commerce Subcommittee on Space, Science and Competitiveness in 2016, Eric Horvitz concurred with the assessment that a key factor in the rate of AI development is 'the availability of unprecedented streams of data, coupled with drops in the cost of storing and retrieving that data'. Other important factors 'include dramatic increases in available computing power, and jumps in the prowess of methods for performing machine learning and reasoning. The past thirty years of AI research also saw the rise and maturation of methods for representing and reasoning under uncertainty.' See Eric Horvitz statement to the US Senate Committee on Commerce Subcommittee on Space, Science and 
by the number of articles that mentioned the term 'deep learning' between 2013 and 2015, the sharp increase in patent applications, and the increase in AI start-up investments. ${ }^{96}$

It seems that humanity has already passed through the three routes described by McCorduck. ${ }^{97}$ We are now climbing the steps toward the next route: singularity. This route is much different from the others since, in many ways, humans might not be able to control their pace - or turn back. None can tell what we might find when we push forward in this direction. Humanity's dreams (or nightmares) may come true.

\section{ASSESSING AI POTENTIAL AND RISKS}

Recent developments have stirred both interest in and concern about AI technology. Several authors have discussed the urgency with which we must think about prudent AI policy and have offered suggestions for regulatory changes that can minimize risks without hindering innovation. The seeds for the current discussion were planted by Obama's administration and its National AI Research and Development (R\&D) Strategic Plan. The US AI Strategic Plan's importance is in shaping priority areas that are unlikely to be addressed by the private sector. Thus, the US plan established objectives for federal-funded projects both within and outside the government. ${ }^{98}$ The Obama administration published two additional reports on future considerations on AI: 'Preparing for the Future of AI' and 'AI and the Economy'. Both reports survey expected changes (market, labour force, etc.) and potential to the US economy and make recommendations. ${ }^{99}$ The reports sparked international interest in AI regulation

Competitiveness, Reflections on the Status and Future of Artificial Intelligence (2016) 3 <erichorvitz.com/Senate_Testimony_Eric_Horvitz.pdf> accessed 3 September 2020. See also Eric Horvitz, 'One Hundred Year Study on Artificial Intelligence: Reflections and Framing' (Stanford University, 2014) <ai100.stanford.edu/reflections -and-framing $>$ accessed 3 September 2020.

96 US AI Strategic Plan (n 19) 12. Lawyers also began expressing their own interest in AI. In 2012, marking 25 years of legal research in the field of AI, the AI and Law journal selected 50 papers from the 13 ICAIL conferences providing an interesting overview of the legal development in the AI field. AI and Law in 50 papers (n 86) 217.

97 McCorduck (n 1).

98 US AI Strategic Plan (n 19) 3. The report identifies seven strategic priorities for federally funded AI research: make long-term investments in AI research; develop effective methods for human-AI collaboration; understand and address the ethical, legal, and societal implications of AI; ensure the safety and security of AI systems; develop shared public datasets and environments for AI training and testing; measure and evaluate AI technologies through standards and benchmarks; and better understand the national AI R\&D workforce needs.

99 Preparing for the Future of AI Report (n 19); AI and the Economy (n 9). 
and framed AI policy in the US and many other countries, including Canada, the UK, and the EU. Even the Trump administration eventually conceded to Obama's report recommendations. ${ }^{100}$ In March 2020, the National Artificial Intelligence Initiative Act of 2020 was introduced as a bipartisan initiative to address AI US policy. The act emphasizes the importance of AI R\&D, and the importance of strengthening collaborations between the government, academia, and the private sector. ${ }^{101}$

In Canada, the 2017-2019 budgets emphasized Canada's strategic plan in the 'digital future', committing \$125 million in its 2017 budget to launch a Pan-Canadian Artificial Intelligence Strategy, and \$1.7 billion over five years for research in the 2018 budget. ${ }^{102}$ The 2017 budget set the stage for building an AI policy in Canada by shifting resources toward AI R\&D. Following the 2017 budget, the federal government has invested heavily in AI, including $\$ 950$ million earmarked to fund the AI superclusters and executing AI strategy. ${ }^{103}$ Canada's commitment to AI research was once again reinforced in 2019 with Prime Minster Justin Trudeau's announcement for a \$2.05 billion investment over 24 years in space robotics, which includes a $\$ 150$ million investment over the next five years for a Lunar Exploration Accelerator Program to help developing technologies in the fields of AI, robotics, and health. ${ }^{104}$

100 See Office of Science and Technology Policy, 'Accelerating America's Leadership in Artificial Intelligence' (The White House, 11 February 2019)<whitehouse .gov/articles/accelerating-americas-leadership-in-artificial-intelligence $>$ accessed 3 September 2020.

101 US, Bill HR 6216, National Artificial Intelligence Initiative Act of 2020, 116th Cong (2020).

102 Ministry of Finance, Budget 2017: Building a Strong Middle Class (22 March 2017) 104 <budget.gc.ca/2017/docs/plan/budget-2017-en.pdf $>$ accessed 3 September 2020. The 2018 budget reinforces Canada's commitment to AI research, see Ministry of Finance, Equality + Growth: A Strong Middle Class (27 February 2018) 85 and 93 $<$ budget.gc.ca/2018/docs/plan/budget-2018-en.pdf > accessed 3 September 2020.

103 ibid 103-104; The Institute for Competitiveness \& Prosperity, From Prediction to Reality: Ontario's AI Opportunity (2018) 18 <competeprosper.ca/uploads/2018 From_prediction_to_reality_Ontarios_AI_opportunity.pdf $>$ accessed 3 September 2020. A 'cluster' is a group of companies that work together on a specific project. A supercluster builds on that idea into a larger scope of the group. The supercluster initiative 'convene[s] industry players, with collaborative organizations, funding, and research institutions to enable projects that individual companies would be incapable of tackling alone due to a lack of funds, ideas, or specific skill sets'. Ontario's AI Opportunity Report, ibid 19.

104 Ministry of Finance, Investing in the Middle Class Budget 2019 (19 March 2019) 106 and $115<$ https://www.budget.gc.ca/2019/docs/plan/budget-2019-en.pdf $>$ accessed 3 September 2020. 
Prominent Canadian scholars have outlined policy considerations that provincial and federal governments should address. ${ }^{105}$ They suggest, for example, imposing a legal status on self-driving cars and other AIs and robots, ${ }^{106}$ and recommend introducing a registration system for advanced robots. ${ }^{107}$ Matthew E Castel and Jean-Gabriel Castel go as far as to support entitling AI to the full protections of the Canadian Charter of Rights and Freedoms, a bold, and somewhat premature, proposal. ${ }^{108}$ Between 2018 and 2020, Canada presented several AI regulations, including the Treasury Board Canada Secretariat directive on Automated Decision-Making (encouraging Canadian institutions to reduce AI systems risks, improving transparency and quality of the data) and the Digital Charter and Strengthening Privacy for the Digital Age (outlining ten principles concerning emerging technologies). ${ }^{109}$

The UK Parliament established the Select Committee on AI 'to consider the economic, ethical and social implications of advances in artificial intelligence'. ${ }^{110}$ In April 2018, the Committee published the AI in the UK: Ready, Willing and Able? report. The Committee expressed concern about using

105 See Matthew E Castel and Jean-Gabriel Castel, 'The Impact of Artificial Intelligence on Canadian Law and Legal Profession' (2016) 46 Adv Q 34 [The Impact of AI on Canadian Law]; Jean-Gabriel Castel and Matthew E Castel, 'The Road to Artificial Intelligence: Has International Law a Role to Play?’ (2016) 14 CJLT 1.

106 The Impact of AI on Canadian Law (n 105) 36.

107 ibid. Similar ideas for registration technology were raised in regard to 3D printing. See Shlomit Yanisky-Ravid and Kennth S Kwan, '3D Printing the Road Ahead: The Digitization of Products When Public Safety Meets Intellectual Property Rights A New Model' (2017) 38 Cardozo L Rev 921.

108 The Impact of AI on Canadian Law (n 105) 37.

109 See Directive on Automated Decision-Making (5 February 2019) <tbs-sct.gc .ca/pol/doc-eng.aspx $\mathrm{id}=32592>$ accessed 3 September 2020; Innovation, Science and Economic Development Canada, Canada's Digital Charter in Action: A Plan by Canadians, for Canadians (May 2019) <https://ic.gc.ca/eic/site/062.nsf/vwapj/ Digitalcharter_Report_EN.pdf/\$file/Digitalcharter_Report_EN.pdf $>$ accessed 3 September $20 \overline{2} 0$. For further reading on Canada AI policy see Gaon and Stedman (n 11). See also Office of the Privacy Commissioner of Canada (OPC), Proposals for Ensuring Appropriate Regulation of Artificial Intelligence (28 January 2020) $<$ www.priv.gc.ca/en/about-the-opc/what-we-do/consultations/consultation-ai/pos_ai 202001> accessed 3 September 2020.

110 The committee appointed by the House of Lords on 29 June 2017. See AI in the UK report (n 26) 2. Prior to the Select Committee, the House of Commons Science and Technology Committee published in September 2016 the Robotics and Artificial Intelligence Report. The Robotics and AI report, along with other parliamentary initiatives (such as the APPG AI - All-Party Parliamentary Group on Artificial Intelligence), addressed the economic, social, and ethical consideration that AI development surfaced. See UK, HC Deb 12 October 2017, vol 145, col 98 < publications.parliament.uk/ $\mathrm{pa} / \mathrm{cm} 201617 / \mathrm{cmselect} / \mathrm{cmsctech} / 145 / 145$.pdf $>$ accessed 3 September 2020. 
biased datasets to train AI and recommended allocating funds to encourage the creation of tools to ensure the quality of datasets. The Committee proposed an 'AI Code', which includes five overarching principles for AI. ${ }^{111}$ Furthermore, the Committee urged the government to consider the adequacy of the legislation and recommended forming clear principles 'to address the legal liability issues of AI'. In considering regulatory measures, the committee expressed reservations from 'blanket AI-specific regulation', stating that existing regulation might suffice at this point. ${ }^{112}$ Following the Committee's work, the UK government moved on several fronts to address AI policy concerns and develop the nation's AI strategy. ${ }^{113}$ The Industrial Strategy AI Sector Deal earmarked $£ 0.95$ billion (complementing the $£ 1.7$ billion from the cross-sectoral Industrial Strategy Challenge Fund) to support the industry sector and implement UK strategy in five key areas: ideas, people, infrastructure, business environment, and places (UK communities). ${ }^{114}$

The EU approach to AI regulations is more proactive in recent years. In 2016, the European Parliament issued a motion for establishing an EU agency for robotics and AI to 'supply public authorities with technical, ethical and regulatory expertise', and addressing liability concerns posed by AI technology. ${ }^{115}$ The EU Parliament's motion was bold and innovative, putting forward important issues such as AI systems' legal status. In June 2017, the Commission

111 AI in the UK report (n 26) 125: '(1) Artificial intelligence should be developed for the common good and benefit of humanity. (2) Artificial intelligence should operate on principles of intelligibility and fairness. (3) Artificial intelligence should not be used to diminish the data rights or privacy of individuals, families or communities. (4) All citizens have the right to be educated to enable them to flourish mentally, emotionally and economically alongside artificial intelligence. (5) The autonomous power to hurt, destroy or deceive human beings should never be vested in artificial intelligence.'

112 AI in the UK report, ibid 126-38. See also the UK government response to the report concurring with the Committee position and advising regulators to review current regulation and identify gaps. See the Secretary of State for Business, Energy and Industrial Strategy, Government Response to House of Lords Artificial Intelligence Select Committee's Report on AI in the UK: Ready, Willing and Able? (June 2018) <parliament.uk/documents/lords-committees/Artificial-Intelligence/AI-Government -Response2.pdf $>35$ accessed 3 September 2020.

113 Establishing the Centre for Data Ethics and Innovation and enacting the Data Protection Act 2018.

114 UK Government, Policy Paper: AI Sector Deal (21 May 2019) <gov.uk/ government/publications/artificial-intelligence-sector-deal/ai-sector-deal\#further -information> accessed 3 September 2020.

115 See European Parliament, Committee on Legal Affairs, 'Motion for a European Parliament Resolution with Recommendations to the Commission on Civil Law Rules on Robotics' (2015/2103(INL), 31 May 2016). 
published its response to the Parliament motion. ${ }^{116}$ Soon after taking office, the new president of the EU Commission, Ursula von der Leyen, pledged to introduce new plans for EU AI policy. ${ }^{117}$ Following this statement, the EU Commission moved forward in shaping the EU AI policy. In February 2020, two important papers were published: a white paper on the EU approach to AI excellence and trust, and a report about AI safety and liability. Both papers are significant in addressing barriers to AI research and legal considerations. ${ }^{118}$ The EU White Paper, for example, highlights a number of considerations for AI legislation, such as strengthening public confidence in AI technology and conformity to the EU's guiding principles. The EU also recommends taking the initiative in legislative changes, proposing taking a risk-based approach to help ensure fair regulatory intervention. ${ }^{119}$ However, even with its recent policy initiatives, it seems that the EU's prudent approach towards AI - as

116 See Commission, 'A Digital Single Market Strategy for Europe' COM (2015) 192 final <eur-lex.europa.eu/legal-content/EN/TXT/?uri=celex\%3A52015DC0192> accessed 3 September 2020; Commission, 'Digitising the European Industry' COM (2016) 180 final <eur-lex.europa.eu/legal-content/EN/TXT/?uri=CELEX: 52016DC0180> accessed 27 April 2020; Commission, 'Building a European Data Economy' COM (2017) 9 final <eur-lex.europa.eu/legal-content/EN/TXT/?uri=COM: 2017:9:FIN> accessed 3 September 2020; Claire Bury, 'Mid-Term Review of the Digital Single Market Strategy (DSM) - a good moment to take stock' (EC, Shaping Europe's digital future, 10 May 2017) <ec.europa.eu/digital-single-market/en/content/ mid-term-review-digital-single-market-dsm-good-moment-take-stock $>$ accessed 3 September 2020. See Council Regulation (EC) 2016/679 of 27 April 2016 of the European Parliament and of the Council on the protection of natural persons with regard to the processing of personal data and on the free movement of such data, and repealing Directive 95/46/EC (General Data Protection Regulation) [2016] OJ 2016, L119 [GDPR].

117 Ursula von der Leyen, Political Guidelines for the Next European Commission, A Union that strives for more: My Agenda for Europe $<\mathrm{https}$ ://ec.europa.eu/commission/ sites/beta-political/files/political-guidelines-next-commission_en.pdf $>$ accessed 3 September 2020.

118 Commission, 'White Paper on Artificial Intelligence: a European Approach to Excellence and Trust' COM (2020) 65 final <ec.europa.eu/info/sites/info/files/ commission-white-paper-artificial-intelligence-feb2020_en.pdf $>$ accessed 3 September 2020 [EU White Paper]; Commission, 'Report on safety and liability implications of AI, the Internet of Things and Robotics' COM (2020) 64 final <ec.europa.eu/info/sites/ info/files/report-safety-liability-artificial-intelligence-feb2020_en_1.pdf $>$ accessed 3 September 2020.

119 EU White Paper (n 118) 17. More recently, the EU Commission presented a bold initiative to harmonize rules on artificial intelligence. See Commission, 'Proposal for a Regulation of the European Parliament and the Council: Laying Down Requirements for Artificial Intelligence (Artificial Intelligence Act) and Amending Certain Union Legislative Acts' COM (2021) 206 final <eur-lex.europa.eu/legal-content/EN/TXT/ ?uri=CELLAR\%3Ae0649735-a372-11eb-9585-01aa75ed71a1> accessed 8 June 2021. 
reflected by its rigorous data protection regulation - is taking a toll on the EU AI project. ${ }^{120}$

China's AI strategy is especially interesting, given China's devotion to AI research and the abundance of data available for AI development. In 2017, China revealed its Next Generation for Artificial Intelligence Plan. China's AI Plan aims to reach world-leading status in some AI fields by 2025, eventually becoming a primary centre for AI by $2030 .{ }^{121}$ China has selected and endorsed specific companies and institutions to focus on developing the AI field, like Alibaba for smart cities and Tencent in health-tech. ${ }^{122}$ Furthermore, in May 2019, a multi-stakeholder coalition between universities, research institutions, and big corporations released the Beijing AI Principles. The principles offer guidelines pertaining to $\mathrm{R} \& \mathrm{D}$, uses of AI technology, and the role of the government. ${ }^{123}$

In the past several years, many countries have released AI policy papers. The EU's AI Watch Report, for example, gathered information on all EU member states' AI strategies. While several member states are still in the process of

120 The EU Commission admitted that the EU is lagging 'behind in private investments'. It is too soon to tell if the EU AI investments by $70 \%$ (reaching 1.5 billion Euro) for 2018-2020 would strengthen EU AI research and development. See Commission, 'Communication from the Commission to the European Parliament, the European Council, the Council, the European Economic and Social Committee and the Committee of the Regions on Artificial Intelligence for Europe' COM(2018) 237 final, 4 and $6<$ ec.europa.eu/transparency/regdoc/rep/1/2018/EN/COM-2018-237 -F1-EN-MAIN-PART-1.PDF> accessed 3 September 2020. See also Jan De Bruyne and Brahim Bénichou, 'Regulating Artificial Intelligence in the European Union' in Giuseppina D'Agostino, Aviv Gaon and Carole Piovesan (eds), Leading Legal Disruption: Artificial Intelligence and a Toolkit for Lawyers and the Law (Thomson Reuters Canada 2021).

121 Department of International Cooperation Ministry of Science and Technology (MOST), Next Generation Artificial Intelligence Development Plan Issued by State Council China's Strengths Creates Innovation Miracles (China Science and Technology Newsletter, 17 September 2017) <fi.china-embassy.org/eng/kxjs/P0 20171025789108009001.pdf> accessed 3 September 2020. See also Huw Roberts et al, 'The Chinese Approach to Artificial Intelligence: An Analysis of Policy, Ethics, and Regulation' [2020] AI \& Soc <https://doi.org/10.1007/s00146-020-00992-2> accessed 3 September 2020.

122 Roberts et al (n 121). Meng Jing and Sarah Dai, 'China recruits Baidu, Alibaba and Tencent to AI "national team"' (South China Morning Post, 21 November 2017) $<$ www.scmp.com/tech/china-tech/article/2120913/china-recruits-baidu-alibaba-and -tencent-ai-national-team $>$ accessed 3 September 2020.

123 Beijing AI Principles https://www.baai.ac.cn/news/beijing-ai-principles-en.html accessed 3 September 2020. 
developing their strategy, most have already shown their commitment to AI. ${ }^{124}$ Other countries have invested and are investing resources in emerging technologies and have introduced regulatory changes concerning AI. It seems that all the key players in the world are interested in investigating AI's potential and coming up with the right AI policy. ${ }^{125}$

Playing the devil's advocate, I wonder why we need governments' investments and supervision? Why should governments support the developments in areas that are currently driven efficiently by large and well-funded corporations? Are there no bigger challenges governments should invest taxpayers' money in? One reason is that the fact that there are more significant risks does not mean we should avoid lower-level risks currently posed by AI. Another reason, as Ryan Calo offered, is that the industry might not be willing to adopt policies or guidelines unless forced to do so. The market is not always the best regulator, and Adam Smith's 'invisible hand' cannot provide the assurances of safety required by the public. This is especially true in markets where profit-maximizing interests foster fake news and foreign government interference in the democratic process. Furthermore, in areas in which there is a higher probability of risk, there is an even more persuasive argument for imposing government restrictions. True, given certain liability factors - the current laws shift the responsibility to damages inflicted by technology to the programmers or owners - there is a strong incentive for companies to self-regulate. However, the fact that several 'big players' are involved in different countries makes this goal of self-regulation an even more significant challenge. On a more practical level, each company might come up with a different set of guidelines and ethical codes for its agenda and business vision.

For some, AI policy means AI laws. ${ }^{126}$ However, AI policy does not necessarily require enacting AI laws and regulations. I share the AI in the UK Report

124 On 10 April 2018, 25 EU countries signed a Declaration of Cooperation on Artificial Intelligence (AI) committing to boost the EU's AI technology, addressing socio-economic challenges, ensuring adequate legal and ethical framework, etc. See EU Declaration of Cooperation on Artificial Intelligence (AI) (Brussels, 10 April 2018) <ec.europa.eu/digital-single-market/en/news/eu-member-states-sign-cooperate -artificial-intelligence $>$ accessed 3 September 2020. According to the recent white paper, 16 member states published their AI strategy, including the UK, Germany, France, the Netherlands, etc. See Vincent Van Roy, AI Watch - National Strategies on Artificial Intelligence: A European Perspective in 2019 (2020) 6.

125 See OECD AI Policy Observatory, Countries \& Initiatives Overview (OECD AI Policy Observatory) <oecd.ai/countries-and-initiatives> accessed 3 September 2020. The US is leading with more than $36 \mathrm{AI}$ initiatives.

126 Ryan Calo has argued that even the use of the term 'policy' in regard to AI is controversial. The Berkman Klein Center at Harvard has chosen to describe policy initiatives concerning AI as an 'Ethics and Governance of Artificial Intelligence Fund.' See 
position against 'blanket AI-specific regulation' or what Calo and others called general AI laws. ${ }^{127}$ Imposing AI regulations, as some countries suggested, can create distraction and uncertainty. However, that does not mean that we should avoid any government intervention. Crafting an AI policy that can foster the positive effects AI might have on society while trying to avoid the adverse effects is wise and timely.

I view policy as the zone between laws and ethics. It can signal to the public and industry where the government is hoping to get without imposing restrictive rules at first. Though policy might eventually translate into laws, there are no guarantees that a particular policy will be adopted. Furthermore, policy discussions among the government, academia, consumers, NGOs, and the industry are the most efficient way to design careful measures that can allow for the development of a given field without endangering public interests. Indeed, we should discuss possible directions that we should take in due course, but imposing strict rules is not wise. ${ }^{128}$

Several scholars have offered thoughts and suggestions for an AI policy roadmap, such as justice and equity, use of force and safety, privacy, and employment. Justice and equity are the capacity to 'program' or 'translate' human values, such as fairness, transparency, accountability, and other moral considerations to algorithms and AI systems. ${ }^{129}$ The concepts of justice, equity, and other abstract forms of thinking are what make humans unique. Developing a set of moral and ethical considerations for AI programs has great potential in eliminating human bias and inequality.

As I shall further discuss in the next chapters, there are indications of design bias in programs. ${ }^{130}$ Since minorities and other disadvantaged groups are not the primary concern of the private sector, there is a high likelihood that without government intervention, structural bias toward these groups will 'echo' within AI programs. This brings me to the first rule in shaping AI policy: act wherever and whenever there is a low probability that the private sector will

Calo - AI Policy (n 16). Indeed, AI poses important ethical questions as well. However, I share Calo's opinion that '[e]thics as a construct is notoriously malleable and contested' and hard to enforce while '[p]olicy - in the sense of official policy, at least - has a degree of finality once promulgated'. ibid 408.

127 The AI in the UK report (n 26) 137.

128 The law tends to lag behind technology. See Lyria Bennett Moses, 'Agents of Change: How the Law "Copes" with Technological Change' (2011) 20 Griffith L Rev 764.

129 Calo - AI Policy (n 16). Alex Campolo and others, The AI Now Report: The Social and Economic Implications of Artificial Intelligence Technologies in the Near Term (AI Now Institute, 22 September 2016) < artificialintelligencenow.com/media/ documents/AINowSummaryReport_3_RpmwKHu.pdf $>$ accessed 3 September 2020.

130 Calo - AI Policy (n 16) 411. 
address an issue by itself. One way the government can affect these concerns is by policing the use of data - the fuel and currency of AI. ${ }^{131}$

Future policy challenges include developing rules that can assist in decision-making processes, anticipating AI programs that may eventually be able to make certain decisions and even replace parts of our legal system. ${ }^{132}$ As with bias and inequality, it initially seems complex and daunting to imagine ways in which AI systems could replace human judges. However, this is not necessarily true: legal standards that currently uphold complex sets of rules might be replaced by AI systems that could prove to be better in providing reliability, accessibility, and predictability. Investing resources in AI decision-making capabilities is an important goal for governments. ${ }^{133}$

The current legal system is based on 'valve concepts' such as good faith, reasonableness, probability, and other concepts that are shaped and decided by judges and lawyers. AI might not require these sets of ambiguous concepts and, therefore, develop a more reliable and predictable way to analyse a legal case and make decisions. The AI 'judge' might provide a solution to one of the most challenging struggles in the legal system - equal sentences and damages. Obviously, not all decision-making can rely on AI, and certain important decisions should always be kept for humans. ${ }^{134}$ Finding a way to teach AI abstract concepts that humans find difficult to define (such as the concept of justice or good faith) might be a misguided approach. ${ }^{135}$ However, creating a set of rules

131 Data is very important for the development of the AI industry and might become an entry barrier as indicated by competition and antitrust agencies around the world. See Canada, Competition Bureau, Big Data and Innovation: Key themes for competition policy in Canada (Ottawa, 19 February 2018) <competitionbureau.gc.ca/eic/ site/cb-bc.nsf/vwapj/CB-Report-BigData-Eng.pdf/\$file/CB-Report-BigData-Eng.pdf> accessed 3 September 2020.

132 See Frank Fagan and Saul Levmore, 'The Impact of Artificial Intelligence on Rules, Standards, and Judicial Discretion' (2019) 93 S Cal L Rev 1; Judge John C. Allen IV, 'Artificial Intelligence' (2020) 59 No 1 Judges' J 1 (ABA special issue).

133 AI can improve the functioning of governments, in both executive function and policymaking. Jamie Berryhill, and others, 'Hello, World: Artificial intelligence and its use in the public sector' (2019) OECD Working Papers on Public Governance, No. 36 <doi.org/10.1787/726fd39d-en> accessed 3 September 2020; Joel Tito, 'Destination Unknown: Exploring the Impact of Artificial Intelligence on Government' (2017) Centre for Public Impact Working Paper < publicimpact.blob.core .windows.net/production/2017/09/Destination-Unknown-AI-and-government.pdf> accessed 3 September 2020; Julian Torres Santeli and Sabine Gerdon, '5 Challenges for Government Adoption of AI' (World Economic Forum, 16 August 2019) <weforum .org/agenda/2019/08/artificial-intelligence-government-public-sector $>$ accessed 3 September 2020

134 Calo - AI Policy (n 16) 414.

135 Though, we could suggest pointers and factors that AI systems would analyse, much like many cases are decided today by 'inferior' human judges. See Samuel Smith 
that AI can follow and embracing AI capabilities to analyse information very quickly is a good start.

Government policy is important in managing these projects, making sure that rules are based on core societal values, creating boundaries and restrictions, preventing bias and inequality, providing funding, and coordinating efforts between key players like academia, the public and private sectors, and coordinating initiatives in other countries.

The second domain in which policymaker considerations are required is human safety and the use of force. AI may eventually make vital decisions that can affect life, such as the decision to shoot a 'hostile' target by automated drones or for a self-driving vehicle to choose between hitting a pedestrian or crashing into a tree. ${ }^{136}$ Indeed, these decisions, while similar, are different in many ways. There is a near consensus internationally that 'kill' decisions should always be reserved for humans and that no AI should be allowed to make these decisions. ${ }^{137}$

It is reasonable to assume that AI programs will be integrated into most computer systems that are currently affecting and regulating our day-to-day lives. AI will increasingly be deployed in various means of transportation (including private cars, trucks, ships, drones, and airplanes); controlling our homes and providing basic services (cleaning and cooking); supporting our elderly; detecting dangers and alerting citizens and law enforcement to them, and more. Certain professions, such as doctors, lawyers, and accountants, will change or adapt in concert with AI technology. These plausible scenarios demonstrate the great potential AI has in preventing accidents and creating a safer and better environment for us all.

Old Brewery (Tadcaster) v Lee (t/a Cropton Brewery) [2011] EWHC 1879 (Ch), [2011] All ER (D) 229 [118]. In the Yorkshire Bitter trade mark case, Mr Justice Arnold suggested factors in order to determine honest practice (that is no different from determining good faith).

136 Bert I Huang, 'Law’s Halo and the Moral Machine' (2019) 119:7 Columbia Law Review 1811. See MIT Moral Machine website $<$ moralmachine.mit.edu $>$ accessed 3 September 2020.

137 See The Campaign to Stop Killer Robots <stopkillerrobots.org> accessed 3 September 2020. A coalition of non-governmental organizations who seek to place a ban on developing lethal autonomous weapons. See also US Department of Transportation, Ensuring American Leadership in Automated Vehicle Technologies-Automated Vehicles 4.0 (January 2020) <www.transportation.gov/sites/dot.gov/files/2020-02/E nsuringAmericanLeadershipAVTech4.pdf $>$ accessed 3 September 2020; Heather M Roff and Richard Moyes, 'Meaningful Human Control, Artificial Intelligence and Autonomous Weapons' (Paper prepared for the Informal Meeting of Experts on Lethal Autonomous Weapons Systems, UN Convention on Certain Conventional Weapons, 11-15 April 2016) <article36.org/wp-content/uploads/2016/04/MHC-AI-and-AWS -FINAL.pdf $>$ accessed 3 September 2020. 
However, with great power comes great responsibility. AI systems are ripe for manipulation in ways that can endanger users unless certain measures are put in place by governments. Establishing safety standards is something governments do all the time in domains like food safety, drug approval, traffic rules, and manufacturing. An international standardization model should be put in place. A good example is the International Organization for Standardization (ISO). The ISO is recognized as a leading institute worldwide and could provide an alternative for AI standardization, which is not regulated/ enforced by countries but is accepted on a voluntary, consensus basis by the international community.

AI systems pose intriguing questions regarding liability (tortious) implications too. This discussion aims to consider who is responsible for AI wrongdoings. ${ }^{138}$ In the context of IP, AI systems could potentially infringe a patent (by producing a patented invention) or infringe authors' work (by using a book as part of its database). However, given that under US patent law, for example, only humans can infringe on a patent, it might be legally impossible to include AI systems as part of a legal suit for infringement. This situation might prove even more challenging when the connection between the AI's programmer and its output (the infringement) is limited. If an AI causes damages, there must be a way to compensate the affected parties. To resolve this potential harm, we must address several issues. First, resolve data barriers, which I discuss in the next chapters. Second, create a database that would be available for AI programs for assessment of infringing potential. However, this solution also poses a challenge - by creating the database, individuals and companies would also expose their inventions, which might not be well accepted. Third, we could require programmers (or companies) to insure their AI systems for possible infringements/damages in the future. ${ }^{139}$

The technological changes will not happen in days (or months). Thus, it is important to address the effect of the transition period as well. If safety standards are to be imposed on AI technology (including self-driving cars, drones, home assistant robots, etc.), the government must devise a way to verify

138 See Omri Rachum-Twaig, 'Whose Robot Is It Anyway?: Liability for Artificial-Intelligence-Based Robots' (2020) 4 U Ill L Rev 1141; Amar Kumar Moolayil, 'The Modern Trolley Problem: Ethical and Economically-Sound Liability Schemes for Autonomous Vehicles' (2018) 9 JL \& Tech \& Internet 1; Gabriel Hallevy, When Robots Kill: Artificial Intelligence under Criminal Law (Northeastern University Press 2013); Matthew U Scherer, 'Regulating Artificial Intelligence Systems: Risks, Challenges, Competencies, and Strategies' (2016) 29:2 Harv JL \& Tech 353.

139 See Bridget Watson, 'A Mind of Its Own - Direct Infringement by Users of Artificial Intelligence Systems' (2017) 58:1 IDEA 65, 66 (in the context of patent infringements). 
whether those standards are met. This process would include government supervision and certification as well as testing. ${ }^{140}$

There are voices arguing that AI regulation could suppress AI technology, and, giving AI potential to human safety, we should avoid placing restrictions. ${ }^{141}$ However, 'safer than humans' is not good enough. ${ }^{142}$ Governments should set basic rules for AI-based systems and, even more urgently, establish how to test current technology. For instance, the government might decide to restrict AI technology to specific areas for trials or pilot runs.

Several scholars call for establishing independent oversight bodies. One proposal sought to form a National Algorithm Safety Board. ${ }^{143}$ Anyone looking to develop and deploy a major new algorithmic system would be required to submit an algorithm impact statement to the board. These statements would include '[s]tandard questions about who the stakeholders are, and what the impacts might be', which would 'ensure that implementers think carefully about potential problems and then propose reasonable solutions'. ${ }^{144}$ Being transparent with the board in advance of deployment helps to minimize concerns about having to later decode the algorithm and its built-in values. It may also be prudent to require black-box testing before approval. ${ }^{145}$ Continuous monitoring would follow the initial approval and would be undertaken by

140 The AI in the UK report (n 26) 138, recommends monitoring government's policies closely 'and react to feedback from academia and industry where appropriate'.

${ }^{141}$ As expressed by the Subcommittee on Digital Commerce and Consumer Protection Chairman concerning self-driving cars: '[This] technology has the potential to dramatically improve safety on our nation's roadways and that is one of the most important reasons to advance the bills we have under consideration today.' Opening Statement of Chairman Greg Walden Subcommittee on Digital Commerce and Consumer Protection Self-Driving Vehicle Legislation (27 June 2017) < docs .house.gov/meetings/IF/IF17/20170627/106182/HHRG-115-IF17-MState-W000791 -20170627.pdf> accessed 3 September 2020.

142 Calo - AI Policy (n 16) 417.

143 The board would have three primary duties: 'planning oversight, continuous monitoring by knowledgeable review boards using advanced software, and a retrospective analysis of disasters'. Ben Shneiderman, 'The Dangers of Faulty, Biased, or Malicious Algorithms Requires Independent Oversight' (2016) 113:48 PNAS 13539 <pnas.org/content/113/48/13538.full.pdf> accessed 3 September 2020. See also the more recent US initiative that directs the Federal Trade Commission (FTC) to require entities that use, store, or share personal information to conduct automated decision system impact assessments and data protection assessments, US, Bill HR 2231, Algorithmic Accountability Act of 2019, 116th Cong (2019).

144 Shneiderman, ibid.

145 Ontario's AI Opportunity Report (n 103) 22-23, echoes this idea, offering to create a regulatory sandbox to incentivize domestic innovation: 'Companies acting within the sandbox would not need to contend with heavy regulatory burdens while still in their infancy and potentially unprofitable.' 
knowledgeable inspectors. This ongoing oversight is similar in theory to the idea of safety inspections in food processing facilities. This would be possible and meaningful because the board would have approved the algorithm before it was delivered to the market, as well as inspected and tested the algorithm through its continuous monitoring program. The board could then work with the algorithm's owner (or any other responsible parties) in order to conduct an inquiry or investigation into the harm that was caused. Another example was presented by Matthew Scherer. Scherer argues for the creation of what he calls an 'Artificial Intelligence Development Act' to be administered by a government agency that can certify and label AI systems as safe. ${ }^{146}$

A different set of policies should be developed to address privacy concerns. Privacy, or the lack thereof, has become a significant concern as people have become more involved with the Internet over the past two decades. We now perform many of our day-to-day activities via the Internet, from using social networks to post pictures (that can pinpoint our exact location) to buying products on Amazon and using GPS-based applications to drive. All these applications and online systems use our data. This availability of data is what enables technological development: AI systems cannot function without access to data. However, the fact that data is so important to the development of AI does not mean that we should not find ways to secure the use of our data and reserve some level of privacy.

The acceleration of AI technology (especially in facial recognition and deep fake methods) will play an essential role in the human rights and privacy discussion. ${ }^{147}$ AI can identify patterns that humans cannot. These capabilities, which we can expect to improve in the future, pose a significant risk to our privacy and threaten to diminish it almost entirely, making everything public to some extent. Even if we allow AI to use information that is shared freely, such as grocery lists or locations, AI pattern recognition might reveal sensitive

146 Matthew U Scherer, 'Regulating Artificial Intelligence Systems: Risks, Challenges, Competencies, and Strategies' (2016) 29:2 Harv JL \& Tech 353, 394.

147 See the recent UK decision holding that using facial recognition technology by policy violates human rights and data protection laws. $R$ (Bridges) $v$ South Wales Police, [2020] EWCA Civ 1058. See also US, Bill HR 3600, Deepfakes Report Act of 2019, 116th Cong (2019). See also US, Bill S 47, Commercial Facial Recognition Privacy Act of 2019, 116th Cong (2019) s 3(a)(1): '[P] rohibit certain entities from using facial recognition technology to identify or track an end-user without obtaining the affirmative consent of the end-user, and for other purposes.' 
information about us. ${ }^{148}$ Though, as indicated above, this technology could also be used for positive purposes like security and safety. ${ }^{149}$

Privacy concerns have intensified in the wake of the COVID-19 pandemic. More and more democratic countries caved to the deployment of technological measures that could use its citizens' data to track their moves, predict the spread of the virus, and minimize infection. ${ }^{150}$ And although most democracies are limiting/restricting the usage of the data, it is foreseeable that once the genie is out of the bottle, it will be very difficult to put it back in again. In other words, when the public is willing to accept (or be indifferent towards) the government's legal privacy breach, and when there is no end in sight, it is unlikely that the technological measures will be put on hold. The COVID-19 effect serves as a 'China-ization' accelerator - pushing the spreading of surveillance and tracking technology by governments worldwide in a similar manner to the 9/11 effect on civil liberties.

Another concern is with access to data and how data is prioritized. Simply put, the ability of AI programs to find solutions to an issue is dependent upon the availability and quality of the data it has access to. As mentioned earlier, data can reflect biases and inequality. Thus, regulating the amount of data, the quality of the data, and the priority with which organizations can access data are paramount. Given that governments control vast amounts of data, the decision of access is first and foremost a policy question. ${ }^{151}$

148 Calo - AI Policy (n 16) 421; See also Tal Zarsky, 'Transparent Predictions' (2013) 4 U Ill L Rev 1503. Israel Private Protection Authority (PPA), for example, has examined the broadcasting companies and streaming services in Israel (including Netflix). Following the investigation, the PPA has published its opinion concluding that the information that is gathered by the broadcasting companies could, potentially, reveal sensitive information about the viewers and is considered 'data' under the Privacy Act and regulations. In consequence, the PPA instructed the companies to secure the information, and to ask for the user/viewer consent for collecting data. See Israel, Private Protection Authority, Statement Concerning Viewers Data by Television Companies (22 April 2018) <gov.il/he/Departments/news/_1tv_supervision> accessed 3 September 2020.

149 Ryan Calo, 'Can Americans Resist Surveillance?' (2016) 83 U Chicago L Rev 23; Calo - AI Policy (n 16) 18.

${ }_{150}$ Natasha Singer and Choe Sang-Hun, 'As Coronavirus Surveillance Escalates, Personal Privacy Plummets' The New York Times (New York, 24 March 2020) $<$ nytimes.com/2020/03/23/technology/coronavirus-surveillance-tracking-privacy .html> accessed 3 September 2020.

151 See Amanda Levendowski, 'How Copyright Law Can Fix Artificial Intelligence's Implicit Bias Problem' (2018) 93:2 Wash L Rev 579. One attempt to regulate data was presented by the EU Commission with the EU General Data Protection Regulation, GDPR (n 116). 
From a public policy perspective, governments should adopt guidelines and regulations that designate the usage of data for specific causes, provide restrictions to preserve the privacy of its citizens, and define the scope of fair data usage. Obviously, this issue raises subsequent questions regarding the way governments can incentivize organizations to use data for public good. Providing free access to government data for specific organizations or companies could prove to be a good policy. In addition, big datasets may also affect the economy: as data are the fuel of AI development, data are worth a lot of money, and therefore the government can leverage it as a means of funding.

The next area that requires government attention is employment. Technological advances in AI will affect the markets. As we learned from the Industrial Revolution and the 1990s Internet blooming, we could expect that AI developments and automation will shake the foundations of our economy. The AI revolution might happen in phases. In the short term, AI technology is unlikely to put humans out of work. Simple and routine tasks would be eliminated, but it will probably take several more years to replace more complex human jobs. ${ }^{152}$ Frank Pasquale, for example, argues that there is a significant difference between human 'holism' - the ability to integrate facts and values to respect the demands of a specific case/event - and the ability to perform tasks by automated AI systems. Pasquale maintains that, as a result, the 'medical care' and 'education' we will receive from AI or robots would be inferior to a human skilled professional. ${ }^{153}$

In order to better prepare for the coming changes, governments should allocate resources and develop specific programmes in technology, computer science, etc. Furthermore, these programmes should be employed on three different levels: blue-collar workers in areas in which there is higher probability to be affected in the coming decades; universities and other higher education institutions; and even primary schools.

152 Harari (n 2) chapter 2.

153 Frank A Pasquale, 'Professional Judgment in an Era of Artificial Intelligence and Machine Learning' (2019) 46:1 Boundary 2, 73. 